\title{
EMANCIPATORY CITIZENSHIP EDUCATION IN ACTION: CREATIVE TEACHING/LEARNING OPTIONS (PART 2)
}

\author{
V Sewpaul \\ University of KwaZulu Natal
}

\begin{abstract}
This is the second part of a two-part series on "Emancipatory citizenship education in action", with a focus on the use of creative teaching and learning options with a group of students taking a course on Human Behaviour and the Social Environment. The student-centred teaching/learning strategies described in this paper allow students to actively engage in discourses of difference of various types, to develop an understanding of, and respect for diversities, to develop self-awareness, and awareness of self in relation to the broader sociopolitical and cultural world. The premise is that the development of such awareness and reflexivity, serves as a precursor to the recognition of the need to work toward change in structural conditions that maintian people in disadvantaged, marginalised and excluded positions.
\end{abstract}

\section{INTRODUCTION}

Part One of this two part article provided the theoretical background to social work and emancipatory citizenship education and described the objectives and underlying epistemology of the first-level Human Behaviour and the Social Environment (HBSE) module offered at the University of Natal, Durban. It detailed the prerequisites for creating a conducive climate for emancipatory citizenship education, and it described the use of Habermas' (1996) theory of communicative action, including discourse ethics and argumentation to facilitate reflexive learning. Part One described the work done during the first term of the first semester. This article describes the use of student-centred creative teaching/learning strategies to demonstrate a holistic view of the life course in the second term of the first semester. Parts One and Two should be read in conjunction with each other for a full appreciation of the content of each article. As much as it is vital to theorise around social work practice, so that we reinforce the theory-practice-theory feedback loop, it is also imperative that educators theorise around their pedagogical practice.

\section{THEORY AND PRACTICE: CREATIVE TEACHING/LEARNING OPTIONS}

The second term of the HBSE course is dedicated to theory and practice in respect of applying the multiple dimensions of human behaviour to each of the major life phases of human development. Alongside the theoretical expositions during formal lectures, students assume full responsibility for demonstrating how the biological, psychological, socio-structural and cultural dimensions apply to the phases of conception, birth and infancy; early childhood; late childhood; adolescence; adulthood; old age and death. For this purpose students have to engage in both individual and group tasks. This serves to respect individual effort and competitiveness, to build confidence and to facilitate co-operative working-together experiences, the benefits of which have been described in Part One. Students are awarded grades individually for their individual tasks. Group presentation is graded as a whole, with each student being awarded the mark that the group gets. The tasks, with some questions as guidelines for students, which have been developed and modified over some time, are described below. 


\section{Groups 1 \& 2}

Each one of you will be given an egg (which represents a baby). You are expected to provide 24hour care for your "infant". If you cannot do so personally, you are expected to provide suitable alternative care. To receive full benefit from the exercise, it is recommended that you get up every three hours (and remain awake for fifteen minutes each time) for the first three days. Remember that in reality this occurs for the first two to three months after the entry of a new-born baby into the family. Keep a journal of your experiences of parenting, including a budget of what it would cost to have and to take care of a baby.

\section{Groups 3 \& 4}

Spend some time in a preschool/day-care centre/playground/park observing young children in action. Is the environment conductive to the needs of children? Observe the interactions between adults and children, the frequency of interactions, the quality of interactions and circumstances under which these interactions occur. How are the needs of differentially-abled children and culturally diverse children catered for?

\section{Groups 5 \& 6}

Talk to a parent or a teacher of a primary school child. What are the characteristics and needs of children at this age? What responsibilities do children have in the home, school and community? How do families, schools and communities facilitate the development of children? What are some of the problems that children of this age might experience?

\section{Groups 7 \& 8}

Interview a parent/parents who have a teenage child/children and the teenager. Are the expectations of teenagers and parents different? If so, how? How do parents perceive and deal with the process of separation? Are there any specific family rules, and how do parents and teenagers view these rules? Are the rules flexible or not? If yes, how are these rules negotiated? How does the family deal with violation of parental expectations/rules? Do the parents and teenagers communicate about such issues as environmental awareness, drugs, pregnancy, HIV/AIDS, dating, sex and child abuse? Is there a relationship between the teenage and middleaged phases of life? If yes, how might this further complicate family relationships?

\section{Groups 9 \& 10}

Talk to a person/couple planning to be married or a couple who have just been married (within the first year of marriage). Try to understand the length and nature of the courtship; type of marriage customary/legal; type of legal marriage and reasons for this choice; parental attitudes towards marriage; their expectations of marriage; planning for children; perceptions of roles of husband/wife/in-laws or other extended family members; plans for living arrangements and costs of setting up a home; issues regarding trans-racial and cross-cultural relationships. You may choose to interview a same-sex couple living together and explore their life experiences and expectations, and societal reactions to them.

\section{Groups 11 \& 12}

Observe and talk to a senior citizen either in a family context or in a residential care setting. What is their experience of life? How do they perceive themselves and how do they think other people perceive them? What are their hopes and expectations? How do people interact with the aged? Do 
the aged have special needs? If yes, what are these needs? Are the physical, emotional, social and spiritual needs of the person whom you are observing and talking to being met?

Each student allocated to a group engages in that particular task and writes an individual report, with integration of theory, with an emphasis on Erikson's epigenetic theory, and the empowerment strategies that are available to families during transitional life periods (Berger, McBreen \& Rifkin, 1996; Berk, 1998; Sewpaul, 1993). Students are informed about the ethical requirement with regard to confidentially and are asked not to include any identifying details in their reports. In addition to this, each group is required to do a class presentation. They are informed that they may use any means to convey the messages. Marks for the group presentations are determined by: structure, creativity, content, ability to reflect the bio-psychosocial and cultural resources and obstacles at each phase of life, participation of all group members in the presentation, and ability to involve the class in discussion.

\section{Bringing the world of reality into the classroom}

While I gave the lectures and facilitated the discussions, the roles were completely reversed for the practice sessions. Through the use of music, poetry, drama, quizzes, chat shows, guest lecturers, formal presentations and discussion, the students brought the world of reality into the classroom. Hours of lectures could not achieve the power of the messages brought to the class by way of the groups with regard to very complex issues, ranging from the local to the global. Many of the presentations included international perspectives with regard to human rights, and the rights of women, children, the disabled and people living with HIV/AIDS. Apart from depicting normative life events, the students introduced several non-normative life events (Berk, 1998), including death, disability, illness, infertility, miscarriages and stillbirth. It is unfortunate that the innovation and creative spirit of the presentations cannot be reproduced in the static form of writing.

Some of the sessions were videotaped and replayed for the purpose of writing this paper. I once reflected with the students that they never failed to amaze me; just when I thought they had exhausted every creative option, they would come up with something even more creative and innovative. Some students spent over twenty hours in preparation and group rehearsals for their presentations. They brought into the classroom all props and costumes that they needed - these included tape recorders, video equipment, Indian and African traditional dress, bridal costumes (ethnic and Western), flowers, telephones, balloons and prizes that some of them offered. Some students also brought in babies, children (generally belonging to the students) and adolescents into their presentations, and invited guest speakers to talk on marriage, becoming a parent, homosexuality and disability. Several students commented that they had more work for this course, compared to their other three courses put together, but that they had thoroughly enjoyed it and had fun while learning. It is impossible to truly represent the richness and variety of themes introduced by students as they highlighted the bio-psychosocial and cultural perspectives of each phase of life, including issues regarding homosexuality, trans-racial and cross-cultural relationships, and systems of patriarchy and its impact on women. The following are a few examples of the students' initiatives.

One group did a most powerful presentation on the phase of early adulthood and marriage. They reproduced in the classroom two marriage ceremonies, one Christian and one Hindu, and engaged the class in a rich discourse on culture and trans-racial relationships. With the "conventional" Christian wedding, they demonstrated the complexities of decision-making and choice in the forms of the "devil" and the "angel", representing the alter-ego of the bridegroom. The voice of the "devil" constantly tried to dissuade the groom from committing to marriage, reminding him of the numerous women and the life of fun and excitement that he would be missing out on if he 
settled for stability and marriage. The "angel" each time countered that his choice was right and that it was about time that he settled for a stable life and family. At the point that the groom said, "I do" the devil collapses in defeat and despair, thus reflecting the age-old theme of the triumph of good over evil. Two White students, visiting from California, played the roles of the bride and groom in the Hindu ceremony, where they were dressed in full Indian regalia, thus lending a somewhat greater salience to cross-cultural issues. One student explained to the class the meaning of each of the rituals conducted during a Hindu ceremony. In another group students brought into the classroom a complete Jewish wedding, depicting both the traditional and the ultra-orthodox versions of Jewish marriage ceremonies. The pre-nuptial and nuptial rites of traditional Zulu weddings were also dramatised and discussed in class. Thus the classes had wonderful opportunities to experience the diversity of traditions, portrayed by the groups with the aim of engendering understanding, respect and appreciation of diversity, lessons that cannot be achieved via formal lectures or any text.

In one group depicting the period of conception, birth and early infancy the focus was on rural traditional life of the Zulus. The roles of the grandmother (gogo), the daughter-in-law (makhoti) in the household and the makhoti's husband, and that of other extended family members, were highlighted. Dressed in traditional wear, the group dramatised and discussed the types of belief systems that existed within Zulu communities and the types of rituals that were conducted during this phase of life. The meaning of children in African communities was highlighted as was the role of ancestors within the African belief system. The group demonstrated the types of pressures, both from the extended family and the husband, on Zulu-speaking Black women to bear sons and very poignantly highlighted the subservient positions of women within such households. Sewpaul (1993) detailed African traditional belief systems and the role of women within traditional African households.

One group demonstrated most powerfully the multiple dimensions of old age, with all roles played by the students. The scene begins with an adolescent, returning home from school, telling his mother that he has a task to do on old age. When she enquires more about it, he says: "My teacher used a big word. I have to do a project on the bio-psychosocial and cultural dimensions of old age." He asks his mother if they can visit his grandmother in the nursing home and she agrees. On the way to the nursing home, she explains to him some of the most important biological changes that accompany old age. On arriving at the nursing home, there is some depiction of the psychological components of ageing through direct interaction with the old people there. The socio-structural was illustrated with the mother having a conversation with the nursing home administrator about conditions in the home, medical care and costs. To exemplify the cultural dimension, the group changed the scene, with a group of adolescents playing ball in a field. One of them is sitting alone. The ball hits him and he is pretty upset about it. He asks his friends: "How can you do this to me? Can't you see I'm in mourning? I just lost my grandmother." A Black student responds: "You're in mourning? Then where is your black patch, how are we to know you're in mourning without it? In my culture we have to wear a black patch on our sleeve so that people know that we are in mourning. So, when did you have the funeral." He responds: "My grandmother died on Monday and we had the funeral on Friday." "You kept your grandmother for a whole week before burying her?" retorts a student representing Islam. "In my culture when someone dies we have to bury them on the same day." "Oh, there was a lot to organise. Relatives had to gather and after the funeral we had cake and tea together," says the adolescent. "You had cake and tea?" asks a somewhat confused Black student, "I cannot imagine going to a funeral where meat is not served. You mean you do not sacrifice an animal? In my culture, we have to sacrifice a goat or cattle. We believe that spilling the blood helps the soul to reach the ancestors." "Oh you with all your stories," squeals the adolescent, "you are making me fed-up. I am going 
home to watch some TV." "Watch TV!" exclaims a student representing Hinduism in disbelief, "we are not allowed to switch on our TV or have any fun for at least forty days?" The adolescent, representing dominant Western culture, walks away frustrated by what he considers to be quite alien beliefs.

As is evident from the above, the presentations provided for some vibrant and interesting reflections on gender, culture, ethnicity, prejudice and ethno-centricism (Berger et al., 1996). Nettleford (1995) very poignantly described the cultural penetration of the West. The intellectual, cultural and psychological control of colonised people, perpetuated via cultural penetration by Western foreign media that assumes the superiority of the North, has contributed to Western cultural hegemony and a subjugation of other, non-Western cultures (Giroux, 1983, 1994; Nettleford, 1995). Thus Giroux $(1994,1997)$ called for an insurgent multiculturalism that questions dominant discourses on multiculturalism that have been used to victimise minority groups, with an emphasis on their deficits and one which presents them as the 'other'. Bringing the world of reality into the classroom allowed for such questioning and for the deconstruction of hegemonic discourses.

The students brought to the classroom experiences of the real world that remain inaccessible to many students. The university is governed by Western ideals, practices and modes of conduct and of teaching, with heterosexuality as the norm. Bringing into the classroom racial, ethnic, gender, religious and sexual diversities allowed students to interact with other realities that they are generally not exposed to and provided for rich discourses on these identified differences. One student, engaging in a reflective videotaped discussion, said:

With the racial and cultural differences ... Talking about our social work class specifically it's not such a large barrier. I mean it is, but everyone's getting to talk about it, deal with it and everyone's trying to understand. So I don't think there is going to be this animosity between us.

Another student commented:

This is really very useful. Many of us don't know anything about other cultures. But when we get our degrees we will not be working with White, or Black, or Indian. We will have to work with all people, and we need to understand different cultures.

While differences were acknowledged and respected, and challenged where they needed to be challenged, the focus was also on in-group variations and across-group similarities (Berger et al., 1996), with an emphasis on the common threads that bind us together as human beings, and on respect for human dignity irrespective of difference. It is important to note that while race is not equivalent to culture, in the South African context a person's cultural beliefs are more often than not linked to the racial and ethnic group from which one comes. Lindiwe, a blind student whose story is discussed in Part One, commented: "I am learning a lot about myself and other people and about the importance of not generalising about people and to treat everybody as individuals ... It has helped me as a blind person to gain a lot of confidence. As a differentially-abled person, I have learnt that we are all differentially-abled in some ways."

\section{CHALLENGES IN THE USE OF SUCH STRATEGIES}

The prerequisite for achieving rational consensus through communicative action and discourse ethics is non-coercive discussion that is free from distorting influences. According to McCarthy (1989:306-307), participants have the “...same chance to employ representative speech acts, to express their attitudes, feelings, intentions ... so that (they) can be truthful in their relations to 
themselves and make their 'inner natures' transparent to other." Every effort was taken to create a teaching/learning environment conducive to maximising the preconditions for argumentation and discourse ethics. Some students' comments in relation to this were:

The information the lecturer gives carries important facts and in group meetings we also do relevant things. The best thing is that she does not only concentrate on what is in the text, but she goes beyond that to help us understand the diversity of human behaviour. There is also use of guest speakers and videos. It is a kind of reciprocity method of learning because the students are also allowed to give their opinions and bring in guest speakers.

We are allowed to take part in the discussions and give our opinions, which I would like to have in all my lectures ... The practical sessions are often fun and a way of learning from our peers, making the material easier to work with.

The atmosphere is relaxed and comfortable. The discussions are very lively. This is the one class that has my full attention. I never fall off to sleep!

However, the reality is that the discourses took place within the context of the classroom. The power dynamics, both perceived and real, in such contexts cannot be underestimated. The power of the educator's paradigm and persuasive appeal should also not be denied. The extent to which these factors influenced the students' responses in respect of HIV/AIDS is open to contention. Given my own views towards anti-retroviral therapy (Sewpaul, 2002), I have no doubt that I was not neutral. When human rights, social justice and life itself are at stake, it is hardly likely that educators can remain neutral and not use their powers of persuasion. Persuasion, that is based on logical argument and ethically sound discourses, does not translate into intimidation. Given that we had not been able to achieve any real consensus with regard to emotionally laden issues such as race, class and gender in the South African context, it is hardly likely that students felt intimidated in expressing their views. It will appear that bearing the burden of the guilt of the consequences of apartheid might be far too difficult for the first generation of post-apartheid privileged South Africans to bear. Thus, a shift in the extreme direction among some students who deny not only the consequences of apartheid, but it would appear the existence of apartheid itself. The perception of reverse discrimination in relation to affirmative action and the emotional reactions to this is also difficult to deal with. Previously advantaged students see affirmative action as thwarting their life opportunities (Sturgeon, 2002).

Students were informed that they could present different views as long as they were able to provide logical and rational argument to support their claims, that there were different ways of knowing and no single truth to life. The idea is not to always reach consensus. Even if this were the aim, it would take a lot more than one semester of work! The main aim was to develop awareness, sensitivity and a critically reflexive stance in relation to the complexities of the South African historical, socio-political, cultural and economic environment, and the global sphere, with the hope that this will provide the springboard for active citizenship participation (Freire, 1970, 1972, 1973; Giroux, 1983, 1994, 1997).

The benefits of the use of the approaches described in this paper can only be fully realised if they are consistently applied within the discipline of social work and across subjects, which students take at university. Unfortunately, the traditional lecture remains the major mode of instruction (Bernstein \& Gray, 1989). When educators, by and large, adopt the expert and transmission mode of education, and treat students as inferior in the classroom, it is a challenge for students to make the shift to an alternative paradigm in isolated contexts. While experiential learning is commonplace in social work, this is not necessarily accompanied with emancipatory pedagogical strategies, reflection and critique. Both the paradigms of educators and the structural barriers to 
adopting alternative ways of teaching need to be examined. One of the challenges to adopting alternative teaching paradigms is that it is time consuming, and huge classes render such alternative paradigms virtually impossible. This posed a major challenge for me in the 2002 class, where we had 108 students. The extended three-hour practice sessions that we had, and the group exercises and presentations enabled the use of communicative action, discourse ethics and the other creative strategies employed by the students.

\section{CONCLUSION}

The power of creative teaching/learning strategies, based on the principles of experiential learning and the life-worlds of students, as described in this article, and the use of Habermas's (1996) theory of communicative action, aimed at emancipatory citizenship education as described in Part One is evident. These strategies allowed students to actively engage in discourses of difference of various types, to develop an understanding of, and hopefully some respect for, diversities, to develop self-awareness, and awareness of self in relation to their broader world and of a critical interrogation of the socio-political order. Despite their strengths, Habermas (1996) makes the point that communicative action and discourse ethics do not provide any substantive orientation for managing practical tasks. While they allow for the development of insight, there is no guarantee that the insight will result in motivated action and they do not provide a blueprint for a normative theory of morality. However, they do offer "....a guide for reconstructing the network of discourses that, aimed at forming opinions and preparing decisions, provides the matrix from which democratic authority emerges" (Habermas, 1996:5). This resonates with the view of Giroux (1983), who contended that subjective intentions alone make little difference to the socio-political order. However, social action (in which social work students receive further education and training in later years) must be preceded by an awareness that makes the need for such action comprehensible (Giroux, 1983; Sewpaul, 2003).

Communicative action and discourse ethics, and the creative strategies described in this article, provide for the development of the kinds of awareness and reflexivity that may facilitate the engagement of students as active and responsible citizens. However, as indicated earlier, for such strategies to have maximum impact, they need to be applied consistently with students, preferably across all disciplines, but at the very least across all modules offered within social work education and training programmes. There is certainly an affinity between the goals of social work and those of emancipatory citizenship education in respect of human rights and social justice. We should therefore strive to make emancipatory citizenship education commonplace and integral to social work education and training.

\section{REFERENCES}

BERGER, R.; McBREEN, J.T. \& RIFKIN, M.J. 1996. Human behaviour: A perspective for the helping professions. New York: Longman.

BERNSTEIN, A. \& GRAY, M. 1989. Working together: An experiential programme dealing with cross-cultural awareness. In: CRITICOS, C. (ed) Experiential learning in formal and nonformal education. University of Natal, Durban: Media Resource Centre.

BERK, L. 1998. Development through the lifespan. London: Allyn \& Bacon.

FREIRE, P. 1970. The pedagogy of the oppressed. Harmondsworth: Penguin Books.

FREIRE, P. 1972. Cultural action for freedom. Harmondsworth: Penguin Books.

FREIRE, P. 1973. Education for critical consciousness. New York: The Seabury Press. 
GIROUX, H.A. 1983. Theory and resistance in education: A pedagogy for the opposition. London: Heinemann Educational Books.

GIROUX, H.A. 1994. Living dangerously: Identity politics and the new cultural racism. In: GIROUX, H.A. \& McLAREN, P. (eds) Between borders: Pedagogy and the politics of cultural studies. New York: Routledge.

GIROUX, H.A.. 1997. Pedagogy and the politics of hope: Theory, culture and schooling. Colorado: Westview Press.

HABERMAS, J. 1996. Between facts and norms: Contributions to a discourse theory of law and democracy. Cambridge: The MIT Press.

HEYWOOD, A. 1999. Political theory: An introduction. London: MacMillan Press Ltd.

McCARTHY, T. 1989. The critical theory of Jurgen Habermas. Cambridge: The MIT Press.

NETTLEFORD, R. 1995. Outward stretch, inward reach: A voice from the Caribbean. New York: The MacMillan Press Ltd.

SEWPAUL, 1993. The family as a focus of intervention for the prevention of mental disorder: An empowerment approach. Social Work/Maatskaplike Werk, 29(3):188-199.

SEWPAUL, V. 2002. The enigma of anti-retroviral therapy: The fight for life. Social Work/ Maatskaplike Werk, 38(4):404-406.

SEWPAUL, V. 2003. Reframing epistemologies and practice through international exchanges: Global and local discourses in the development of critical consciousness. In: DOMINELLI, L. \& BERNARD, W.T. (eds) Broadening horizons: International exchanges in social work. Aldershot: Ashgate.

STURGEON, S. 2002. Developing cultural awareness in human service professionals: A personal journey. Social Work/Maatskaplike Werk, 38(2):173-181.

Prof V Sewpaul, Centre for Social Work, University of KwaZulu Natal, Durban, South Africa. 